\title{
Ice nucleation and cloud microphysical properties in tropical tropopause layer cirrus
}

\author{
E. J. Jensen ${ }^{1}$, L. Pfister ${ }^{1}$, T.-P. Bui ${ }^{1}$, P. Lawson ${ }^{2}$, and D. Baumgardner ${ }^{3}$ \\ ${ }^{1}$ NASA Ames Research Center, Moffett Field, CA, USA \\ ${ }^{2}$ SPEC Inc., Boulder, CO, USA \\ ${ }^{3}$ Centro de Ciencias de la Atmosfera, Universidad Nacional Autonoma de Mexico, Circuito Exterior, Mexico
}

Received: 11 September 2009 - Published in Atmos. Chem. Phys. Discuss.: 1 October 2009

Revised: 24 December 2009 - Accepted: 15 January 2010 - Published: 5 February 2010

\begin{abstract}
In past modeling studies, it has generally been assumed that the predominant mechanism for nucleation of ice in the uppermost troposphere is homogeneous freezing of aqueous aerosols. However, recent in situ and remotesensing measurements of the properties of cirrus clouds at very low temperatures in the tropical tropopause layer (TTL) are broadly inconsistent with theoretial predictions based on the homogeneous freezing assumption. The nearly ubiquitous occurence of gravity waves in the TTL makes the predictions from homogeneous nucleation theory particularly difficult to reconcile with measurements. These measured properties include ice number concentrations, which are much lower than theory predicts; ice crystal size distributions, which are much broader than theory predicts; and cloud extinctions, which are much lower than theory predicts. Although other explanations are possible, one way to limit ice concentrations is to have on the order of $50 \mathrm{~L}^{-1}$ effective ice nuclei (IN) that could nucleate ice at relatively low supersaturations. We suggest that ammonium sulfate particles, which would be dry much of the time in the cold TTL, are a potential IN candidate for TTL cirrus. However, this mechanism remains to be fully quantified for the size distribution of ammonium sulfate (possibly internally mixed with organics) actually present in the upper troposphere. Possible implications of the observed cloud microphysical properties for ice sedimentation, dehydration, and cloud persistence are also discussed.
\end{abstract}

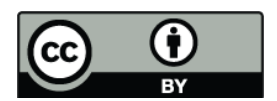

Correspondence to: E. J. Jensen (eric.j.jensen@nasa.gov)

\section{Introduction}

Cirrus occur frequently in the Tropical Tropopause Layer (TTL, typically defined as the region between the maximum convective detrainment level $(\simeq 12-13 \mathrm{~km})$ and the level in the lower stratosphere where the composition and dynamics become stratospheric $(\simeq 19-20 \mathrm{~km})$; Fueglistaler et al., 2008). For example, satellite observations indicate that thin cirrus are present in the tropical uppermost troposphere over the western Pacific during Boreal winter about $50-80 \%$ of the time (Wang et al., 1996; Yang et al., 2009; Massie et al., 2009). Cirrus in this region of the atmosphere are important for a number of reasons. Thin cirrus formed near the cold tropical tropopause can freeze dry air ascending through the TTL, effectively regulating the stratospheric humidity (Gettelman et al., 2002; Jensen and Pfister, 2004; Fueglistaler et al., 2005). TTL cirrus provide the necessary radiative heating to balance slow ascent through the TTL (Corti et al., 2006). In addition, given their low temperature, they exert a positive radiative forcing (warming) on the climate system.

Recent airborne science missions using high-altitude aircraft have provided unprecedented information about the microphysical properties (ice crystal concentrations, size distributions, habits, etc.) of these clouds. In particular, the NASA WB-57 flights during the Costa Rica Aura Validation Experiment (CRAVE) included extensive sampling of very cold, thin cirrus just below the tropical tropopause (Lawson et al., 2008). In addition to the in situ measurements, the Cloud-Aerosol Lidar with Orthogonal Polarization (CALIOP) instrument on-board the CALIPSO satellite is providing a wealth of information about TTL cirrus properties, occurrence frequencies, and extinctions on a global scale. 
We focus here on the thin cirrus formed in situ at very low temperatures just below the tropical tropopause. We show that the microphysical properties of these clouds indicated by the recent measurements are very different from what would be expected if, as is generally assumed in modeling studies, ice nucleation is dominated by homogeneous freezing of aqueous aerosols. Numerical simulations indicate that, even with moderate cooling rates, homogeneous freezing should produce much larger ice concentrations than are indicated by the observations. Also, the sudden production of many ice crystals by the homogeneous nucleation process should result in much narrower ice crystal size distributions than the measurements indicate. Lastly, we show that the extinctions indicated by global simulations of TTL cirrus assuming homogeneous freezing nucleation are much larger than the extinctions indicated by CALIPSO measurements. The implications of the observed cloud microphysical properties are discussed.

\section{TTL cirrus microphysical properties predicted by ho- mogeneous nucleation theory}

Before presenting measurements of TTL cirrus microphysical properties, we discuss the expectations from conventional theoretical treatments of ice nucleation processes in the upper troposphere. In several past modeling studies, it has been assumed that the dominant mechanism for production of ice crystals at low temperatures is homogeneous freezing of aqueous aerosols (e.g. Kärcher and Ström, 2003; Jensen and Pfister, 2004; Jensen et al., 2005; Kay and Wood, 2008). Here, we use a parcel model with detailed microphysics to investigate the sensitivity of ice concentrations produced by homogeneous freezing to cooling rates and wave-driven temperature oscillations. Since the effects of particle sedimentation cannot be treated in a parcel model, we primarily use these calculations to examine the initial ice concentrations produced by a nucleation event. Cloud processes such as entrainment dilution, differential sedimentation, and aggregation will conspire to gradually reduce ice concentrations as the clouds age. Investigation of the effects of the full range of cloud processes on ice concentrations and size distributions are the subject of a follow-on study. We emphasize here that the parcel model simulations only indicate the maximum potential ice concentration that can be produced by homogeneous freezing.

For the parcel-model simulations, we use the Community Aerosol Radiation Model for Atmospheres (CARMA), which treats cloud and aerosol processes using bin microphysics. Aerosol and ice crystal size distributions are resolved with 60 size bins each, with the successive size bins having a volume ratio of 1.4. Homogeneous freezing of aqueous aerosols is treated using the parameterization described by Koop et al. (2000). Following Kärcher and Lohmann (2002), we start with a log-normal aerosol size dis-

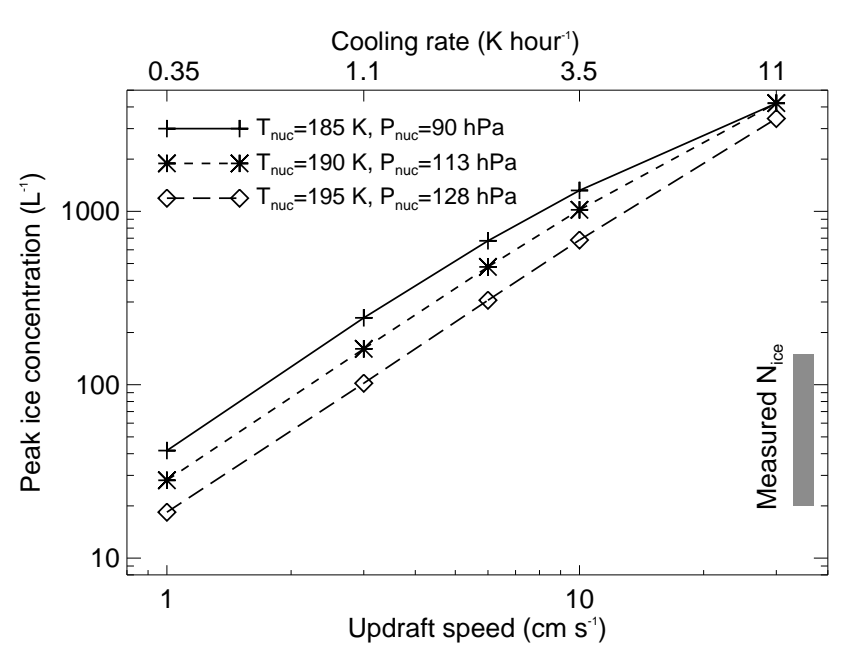

Fig. 1. The sensitivity of peak ice concentration predicted by parcel model simulations of homogeneous aerosol freezing to updraft speed and the temperature at which nucleation occurs. Cooling rate (updraft speed) is clearly the dominant factor controlling peak ice concentration. For comparison, we show the range of measured ice concentrations (presented in Sect. 4).

tribution with a total particle concentration of $2500 \mathrm{~cm}^{-3}$, a mode radius of $0.055 \mu \mathrm{m}$, and a geometric width of 1.6. Results are relatively insensitive to aerosol size distribution or composition. The model treats the exchange of vapor between growing or sublimating ice crystals and water vapor.

A number of modeling studies have shown that if ice nucleation occurs via homogeneous freezing, the resulting ice concentration is primarily controlled by cooling rate, with aerosol abundance having a minor effect (e.g., Jensen and Toon, 1994; Kärcher and Lohmann, 2002). At low temperatures and with moderate-to-rapid cooling rates, the ice concentration could become comparable to the concentration of aerosols available, in which case ice concentration could be controlled by aerosol abundance (Kay and Wood, 2008). However, the aerosol concentration in the tropical upper troposphere is always much larger $\left(>10 \mathrm{~cm}^{-3}\right)$ (Brock et al., $1995)$ than the measured ice concentrations $\left(<200 \mathrm{~L}^{-1}\right)$ discussed below.

Figure 1 shows the dependence of maximum ice concentration produced by homogeneous freezing on adiabatic cooling rate (updraft speed) for conditions in the tropical uppermost troposphere. As other studies have shown, there is some dependence on temperature, but cooling rate is the dominant controlling factor. Only with updraft speeds less than a few $\mathrm{cm} \mathrm{s}^{-1}$ will the peak ice concentration remain within the range of observed ice concentrations at tropical tropopause temperatures. (Measured ice concentrations are discussed in the following section.) The primary reason that homogeneous nucleation produces such large ice concentrations is the assumption that the supersaturation threshold for freezing 


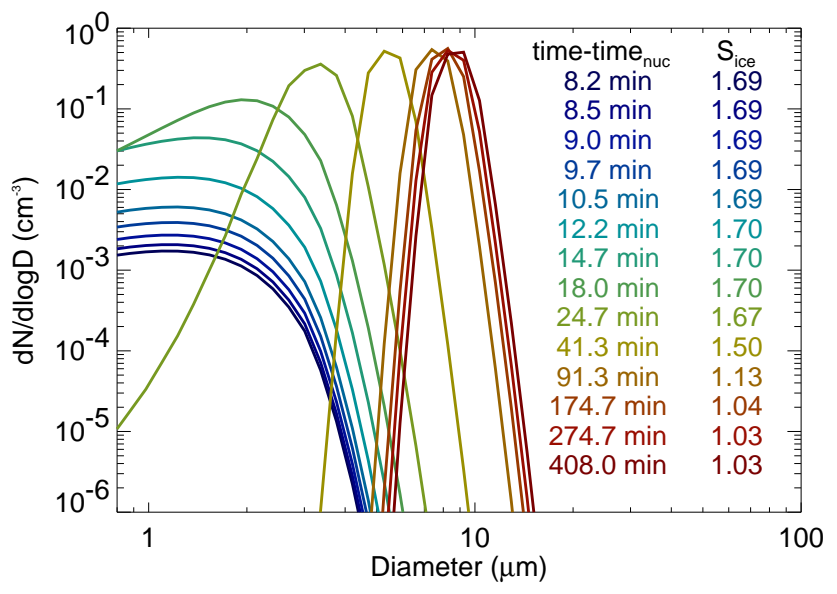

Fig. 2. The evolution of ice crystal size distribution from a parcel model simulation with a slow $\left(1.3 \mathrm{~cm} \mathrm{~s}^{-1}\right)$ uplift are shown. $\mathrm{Nu}-$ cleation occurs at $190 \mathrm{~K}$. Homogeneous freezing results in a narrow size distribution in the mature cloud.

of aerosols is independent of aerosol composition. As a result, when the supersaturation increases past this threshold, homogeneous freezing of many aerosols can occur very quickly.

Along with high ice concentrations, homogeneous freezing nucleation is expected to produce clouds with narrow ice crystal size distributions. Figure 2 shows the evolution of ice crystal size distribution from a parcel model simulation with a cooling rate slow enough (adiabatic ascent rate of $1.3 \mathrm{~cm} \mathrm{~s}^{-1}$ ) slow enough to produce ice concentrations comparable to the measured values presented below. Ice nucleation occurs within a time span of about $10 \mathrm{~min}$, then the ice crystals grow to about $10 \mu \mathrm{m}$ diameter and quench the supersaturation within a few hours. Since all of the ice crystals were nucleated at about the same time, they grow together and end up about the same size in the mature cloud, resulting in the narrow size distribution. We caution again here that it is unrealistic to simulate the evolution of a cloud significantly beyond the point of nucleation with a parcel model because sedimentation will become important. However, even in onedimensional simulations of cirrus formation near the tropical tropopause driven by moderate cooling, homogeneous freezing produces narrow size distributions within a particular altitude range (see Fig. 8 of Jensen et al. (2008)).

It is arguably unrealistic to assume that ice nucleation in the TTL is typically driven by only synoptic-scale motions with updraft speeds no larger than $\simeq 3-4 \mathrm{~cm} \mathrm{~s}^{-1}$. Temperature variability driven by mesoscale gravity waves are a nearly ubiquitous feature in aircraft measurements of temperature in this region of the atmosphere (Bacmeister et al., 1996; Fritts and Nastrom, 1992). As an example from CRAVE, Fig. 3 shows about $7.5 \mathrm{~min}$ of $20 \mathrm{~Hz}$ meteorological data taken with the WB-57 Meteorological Measure-

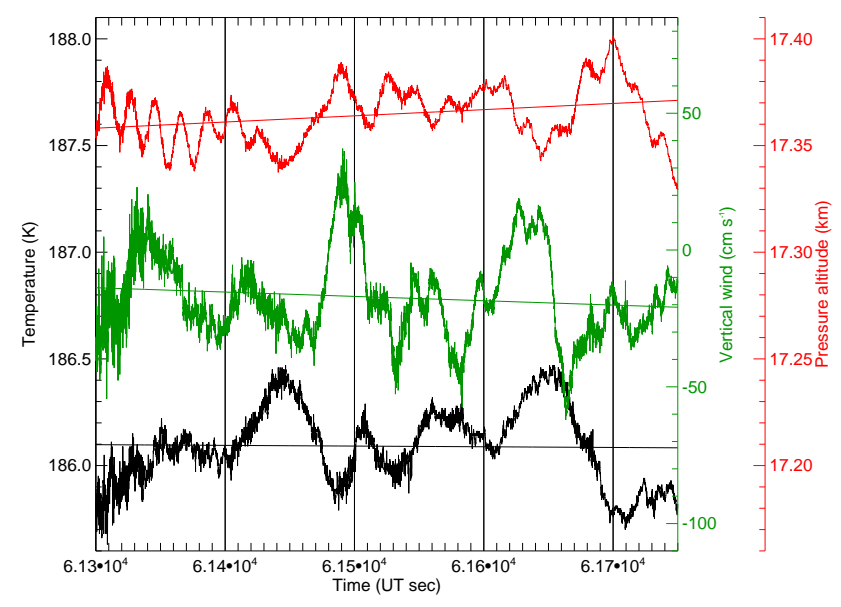

Fig. 3. A $7.5 \mathrm{~min}$ time series of WB-57 temperature (black), vertical wind (green), and pressure altitude (red) measurements is shown for a flight segment on 1 February 2006 during which thin cirrus were sampled. The quasi-periodic, 1-min temperature fluctuations lagging the vertical wind oscillations by about a quarter cycle indicate the presence of gravity waves. The oscillations in pressure altitude are not reflected in the vertical wind or temperature fields.

ment System (Scott et al., 1990) over a fairly level section of the 1 February flight during which thin TTL cirrus were sampled. The fluctuations are irregular, as would be expected from a superposition of waves from a variety of distant sources. The vertical velocities have characteristic amplitudes of about $20-30 \mathrm{~cm} \mathrm{~s}^{-1}$. We can see quasi-periodic fluctuations in temperature about a minute long $(\simeq 10 \mathrm{~km}$ for the $200 \mathrm{~m} \mathrm{~s}^{-1}$ speed of the aircraft), which lag the vertical wind by about a quarter cycle. This phase behavior is expected for a gravity wave where vertical wind fluctuations advect the vertical potential temperature gradient. The intrinsic period of these fluctuations is close to the Brunt-Väisälä period derived from the vertical temperature gradients from the Microwave Temperature Profiler (Denning et al., 1989). Their short period indicates that these waves are vertically trapped, which means that they could have sources at a substantial horizontal distance from the point of observation. The fluctuations are thus physically self-consistent.

Temperature oscillations can drive localized rapid cooling that has the potential to increase ice concentrations generated by homogeneous freezing. The impact of gravity-wave temperature oscillations on ice concentration statistics has been discussed in past modeling studies (Jensen and Pfister, 2004; Kärcher and Ström, 2003). Here, we go a step further and provide an analysis of the impact of different wave frequencies and phase offsets on ice concentrations.

If we consider a case with a single wave frequency, the maximum enhancement in ice concentration will be achieved if ice nucleation occurs in the phase of the wave where cooling is maximized. However, the ice nucleation event is not 
instantaneous; Under tropical tropopause conditions with a cooling rate of $1 \mathrm{~K} \mathrm{~h}^{-1}$ (corresponding to $\simeq 3 \mathrm{~cm} \mathrm{~s}^{-1}$ adiabatic ascent), the time for homogeneous freezing to increase the ice concentration from $5 \%$ to $95 \%$ of its maximum value is about $4 \mathrm{~s}$. If the wave-driven cooling reaches its minimum temperature before the ice nucleation event is complete, nucleation will be shut off prematurely, potentially resulting in a peak ice concentration even lower than would have occurred in the absence of a wave.

Figure 4 shows examples of waves with different phase offsets causing either suppressed or enhanced ice concentration. In these examples, a wave with a period of $30 \mathrm{~min}$ and a vertical wind amplitude of $24 \mathrm{~cm} \mathrm{~s}^{-1}$ is superimposed on a $3 \mathrm{~cm} \mathrm{~s}^{-1}$ adiabatic cooling. The wave phase in the first case (Fig. 4a) results in the temperature reaching a minimum (ice saturation reaching a maximum) shortly after ice nucleation starts. The ice concentration is limited to $40 \mathrm{~L}^{-1}$, and by the time the temperature goes through a deeper minimum $30 \mathrm{~min}$ later, the vapor has been depleted by growth of the existing ice crystals, and no further nucleation occurs. Figure $4 \mathrm{~b}$ shows the result of wave phase being ideal for enhancing ice concentration. Ice nucleation begins when the cooling rate is maximum, and the rapid cooling continues until enough ice crystals $\left(\simeq 3000 \mathrm{~L}^{-1}\right)$ are produced such that their growth rapidly depletes the vapor concentration and quenches further ice nucleation. The peak ice concentration variation with wave phase (Fig. 4c) shows rapid increases and decreases occurring as phase changes slightly. Over most of the range of wave phase, the peak ice concentration is considerably enhanced over that produced without the wave $\left(240 \mathrm{~L}^{-1}\right.$ for the $3 \mathrm{~cm} \mathrm{~s}^{-1}$ background updraft speed).

The peak ice concentrations (both the maximum at optimum phase and the average over phase) versus wave period are shown in Fig. 5 for wave periods ranging from near the Brunt Vaisala period ( $\simeq 5 \mathrm{~min}$ ) up to a few hours. The wave amplitudes for different periods were taken from the spectrum presented by Jensen and Pfister (2004). At the lowest wave periods, the enhancement of peak ice concentrations by wave-driven temperature oscillations is not very strong because the wave period is comparable to the time scale for a nucleation event, and, as discussed above, the nucleation process can be shut off before a nucleation event is complete. In fact, very high-frequency waves can decrease ice concentrations. The maximum enhancement of ice concentration occurs for waves with periods near $30 \mathrm{~min}$. For such waves, the cooling rate can be large, and the wave period is significantly longer than the nucleation time, such that nucleation events can occur within the rapid-cooling phase of the wave. As the period increases beyond $30 \mathrm{~min}$, the peak ice concentration decreases because the wave-driven cooling rate decreases; however, the peak ice concentrations in the waves still remain considerably higher than what would be achieved by slow cooling in the absence of a wave.
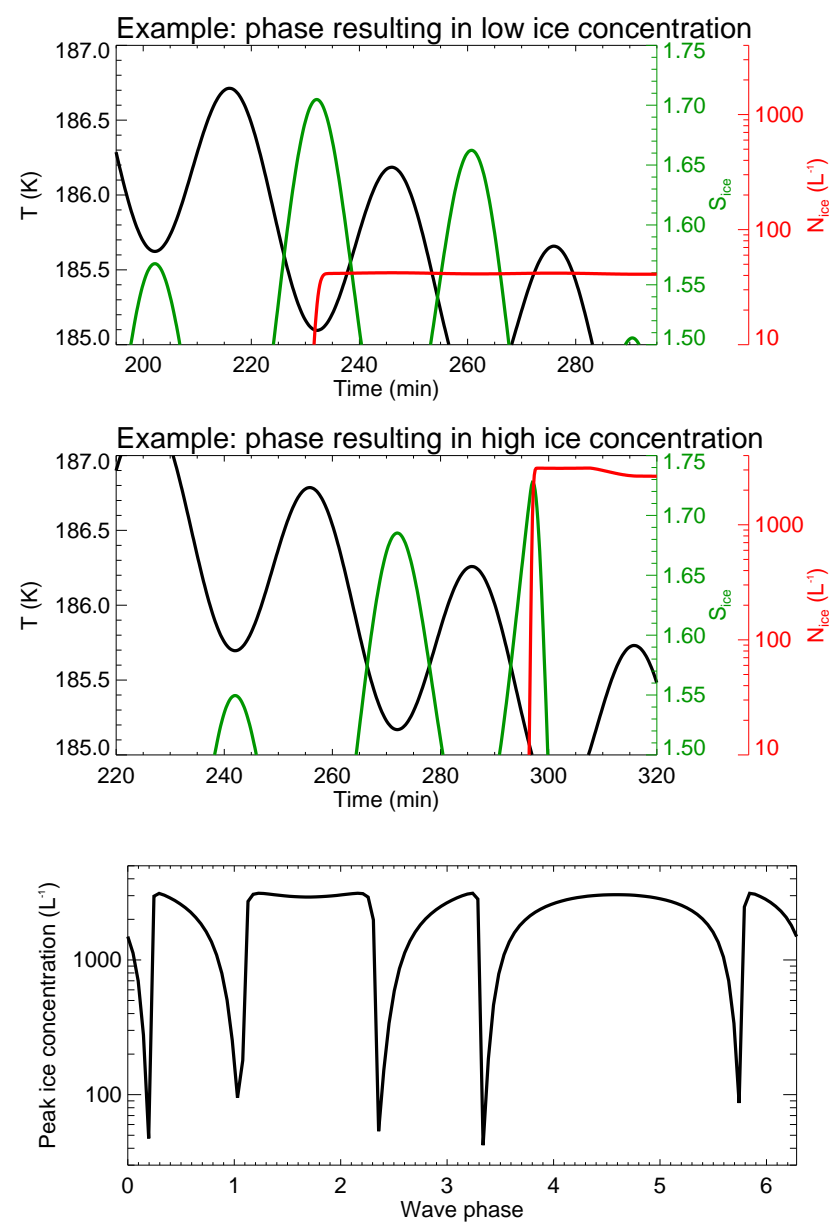

Fig. 4. Time series of temperature (black), ice saturation ratio (green), and ice concentration are shown from parcel model simulations with a gravity wave (period $=30 \mathrm{~min}$, amplitude $=24 \mathrm{~cm} \mathrm{~s}^{-1}$ ) superimposed on slow cooling. Top panel: an example where the wave phase results in a peak ice concentration well below that which would have been produced in the absence of a wave; middle panel: an example where the wave results in strongly enhanced peak ice concentration; bottom panel: peak ice concentration versus wave phase offset.

Lastly, we consider the more realistic scenario of a spectrum of gravity waves superimposed on a slow cooling. Again, we use the spectrum specified by Jensen and Pfister (2004). Phase offsets for individual wave frequencies in this spectrum are chosen by a random number generator. Motivated by the dependence on wave phase offset discussed above, we have run a large number of realizations with different seeds for the random number generator. As shown in Fig. 6, the result is a broad range of peak ice concentrations. However, in the majority of the realizations, the peak ice concentration is significantly higher than what would be generated with slow, synoptic cooling alone and also considerably higher than the measured ice concentrations described below. 


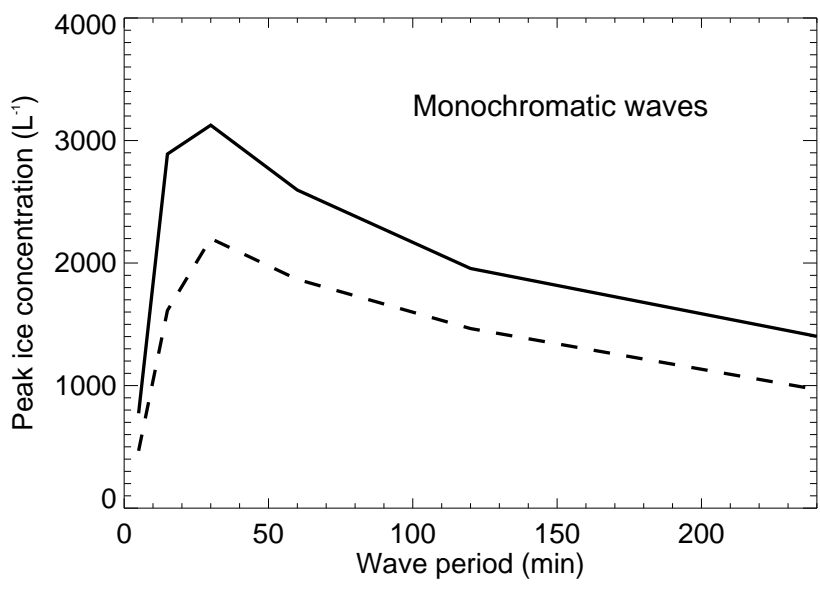

Fig. 5. The peak ice concentration at optimum phase offset (solid curve) and the peak ice concentration averaged over phase offset (dashed curve) are plotted versus wave period for parcel-model simulations with monochromatic waves superimposed on slow cooling. The wave amplitude versus period was taken from the spectrum presented by Jensen and Pfister (2004).

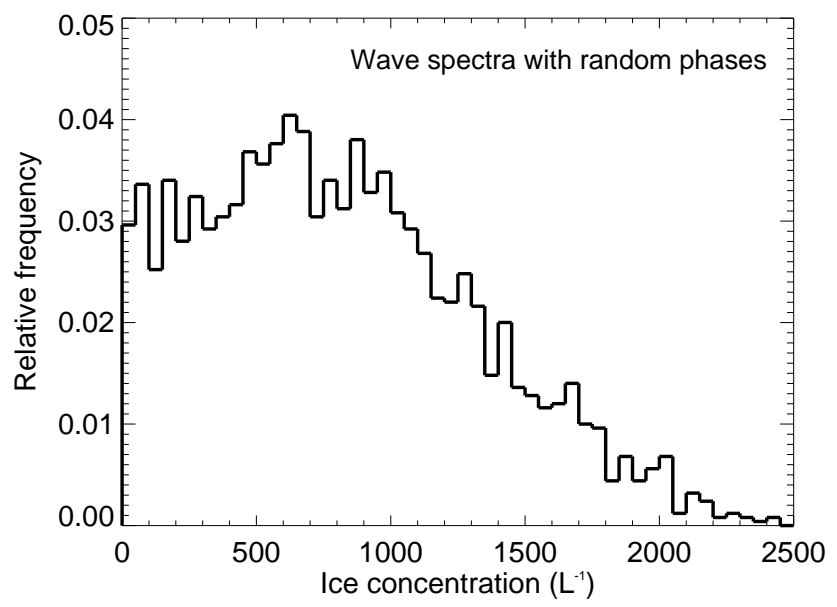

Fig. 6. The frequency distribution of peak ice concentrations from a large number of parcel model simulations with spectra of waves superimposed on slow cooling is shown. In each simulation, a different seed was used for the random number generation of phase offsets for each wave frequency in the spectrum.

\section{TTL cirrus measurements}

For evaluation of TTL cirrus ice production processes, we compare these theoretical expectations with measurements of ice number concentrations, ice crystal size distributions, and cloud extinctions. For the ice concentrations and size distributions, we focus on the extensive sampling of cold TTL cirrus with high-altitude aircraft during CRAVE. As described in detail by Lawson et al. (2008), TTL cirrus were sampled for many hours on multiple flights with the NASA WB-57 aircraft. The key instruments for measuring TTL cirrus microphysical properties were the Cloud, Aerosol, Precipitation Spectrometer (CAPS) and the Two Dimensional Stereo (2D-S) probe. CAPS consists of two separate instruments housed in the same package: the Cloud Aerosol Spectrometer (CAS) retrieves particle sizes in the size range of 0.5$50 \mu \mathrm{m}$ by measuring light scattered off the particles (Baumgardner et al., 2001); the Cloud Imaging Probe (CIP) captures two-dimensional images of ice crystals with sizes ranging from about 25 to $1550 \mu \mathrm{m}$.

The 2D-S probe consists of two independent, identical imaging instruments housed in one canister. 2D-S is similar to CIP and other imaging probes except that it has a smaller pixel size $(10 \mu \mathrm{m})$ and faster electronics, resulting in extension of size distributions down to $\simeq 10 \mu \mathrm{m}$ (Lawson et al., 2006). It is certainly possible that considerable numbers of ice crystals exist that are smaller than the minimum detectable 2D-S size, particularly at the cold tropical tropopause where very little water vapor is available for depositional growth. However, the CAS probe should provide a measure of concentrations in the $1-10 \mu \mathrm{m}$ size range.

There has recently been considerable discussion in the literature about artifacts from shattering of large crystals on the instrument housing resulting in exaggerated concentrations of small crystals reported by these probes (e.g. Field et al., 2003, 2006; McFarquhar et al., 2007; Heymsfield, 2007; Jensen et al., 2009). Although the problem is more acute for instruments such as the CAS probe that ingest ice crystals through an inlet, shattering of large crystals on the detector arms of probes like CIP and 2D-S can also result in artifacts reaching the sample volume and spurious counts of small crystals. In the 2D-S dataset, post-processing analysis using interarrival times identifies and removes shattering artifacts based on the assumption that ice crystal spacings in the natural cloud are Poisson distributed and shattering artifacts appear as clusters of closely spaced particles (Baker et al., 2009). In the CRAVE measurements presented here, crystal shattering is likely not a significant problem since the cold TTL cirrus contain vanishingly few crystals large enough (approaching $100 \mu \mathrm{m}$ ) to produce shattering artifacts (Lawson et al., 2008). Further, the result emphasized below is that TTL ice concentrations are surprisingly low. If the measurements were enhanced by shattering artifacts, then the natural ice concentrations would be even lower.

For comparison, we also present CAPS ice concentrations from a somewhat warmer $(\simeq 200 \mathrm{~K})$, in situ-formed cirrus layer sampled near the subtropical tropopause during the Cirrus Regional Study of Tropical Anvils and Cirrus Layers Florida Area Cirrus Experiment (CRYSTAL-FACE) on 13 July 2002 (Jensen et al., 2005). In this case, larger crystals were present than in the CRAVE TTL cirrus, and shattering artifacts are somewhat more of a concern. Taking $60 \mu \mathrm{m}$ as a conservative lower limit for the size of crystals that can potentially shatter, the maximum ice water content (IWC) of 
crystals that might shatter and produce artifacts in the 13 July cirrus layer indicated by CIP was $0.0006 \mathrm{~g} \mathrm{~m}^{-3}$. A recent analysis of CAPS and 2D-S anvil cirrus measurements indicated a strong linear correlation between spurious CAS ice concentration and large-crystal IWC: $N_{\mathrm{CAS}} \approx 3.56 \times 10^{4} \mathrm{IWC}$ (Jensen et al., 2009). Using this relationship as an approximate guide, we estimate that shattering artifacts likely contributed no more than $\approx 20 \mathrm{~L}^{-1}$ to the ice concentration measured by CAS in the 13 July tropopause cirrus layer.

For global measurements of TTL cirrus, we turn to the Cloud-Aerosol Lidar with Orthogonal Polarization (CALIOP) instrument on-board the CALIPSO satellite. This instrument is providing unprecedented information about TTL cirrus occurrence frequency and regional distribution (e.g., Yang et al., 2009). Here, we use the CALIOP Level 2 measurements of cloud extinction (Anselmo et al., 2007). The direct measurement from CALIOP is actually attenuated backscatter. Calculation of extinction requires assumptions about the so-called "lidar ratio" (extinction to backscatter ratio) as well as the multiple scattering factor (Young and Vaughan, 2009). Yang et al. (2009) provide a detailed analysis of estimations of lidar ratio and multiple scattering factor. They estimate the uncertainty in derived extinction is approximately $30 \%$.

\section{TTL cirrus ice concentrations and size distributions}

\subsection{Ice crystal concentrations}

Microphysical measurements of thin cirrus formed in the TTL from several high-altitude research aircraft experiments have been reported in the literature. These measurements include NASA WB-57 flights made in the 1970s (Heymsfield, 1986; McFarquhar et al., 2000) and WB-57 flights from recent campaigns based in Costa Rica, as well as recent campaigns using the Geophysica aircraft (Krämer et al., 2009). Instruments used to sample the clouds include an Axially Scattering Spectrometer Probe (ASSP) and a OneDimensional Cloud (1DC) particle probe (McFarquhar et al., 2000), a formvar replicator (Heymsfield, 1986), Forward Scattering Spectrometer Probes (FSSP), CAPS, and 2D-S. We focus first on the measured ice number concentrations. As reported by Lawson et al. (2008) and Krämer et al. (2009) the ice concentrations are typically below $100 \mathrm{~L}^{-1}$; for example, the Costa Rica Aura Validation (CRAVE) mission measurements with 2D-S indicate mean TTL cirrus ice concentrations of $66 \mathrm{~L}^{-1}$; the largest ice concentration observed in these clouds was $189 \mathrm{~L}^{-1}$ (Lawson et al., 2008). Figure 7 shows ice concentration frequency distributions measured by 2D-S and CAPS in the TTL cirrus layer sampled on 1 February 2006. The CAPS and 2D-S ice concentrations are almost exclusively less than $100 \mathrm{~L}^{-1}$. TTL cirrus ice concentrations measured on other CRAVE flights were comparably low. The pilots were instructed to porpoise up and down through the

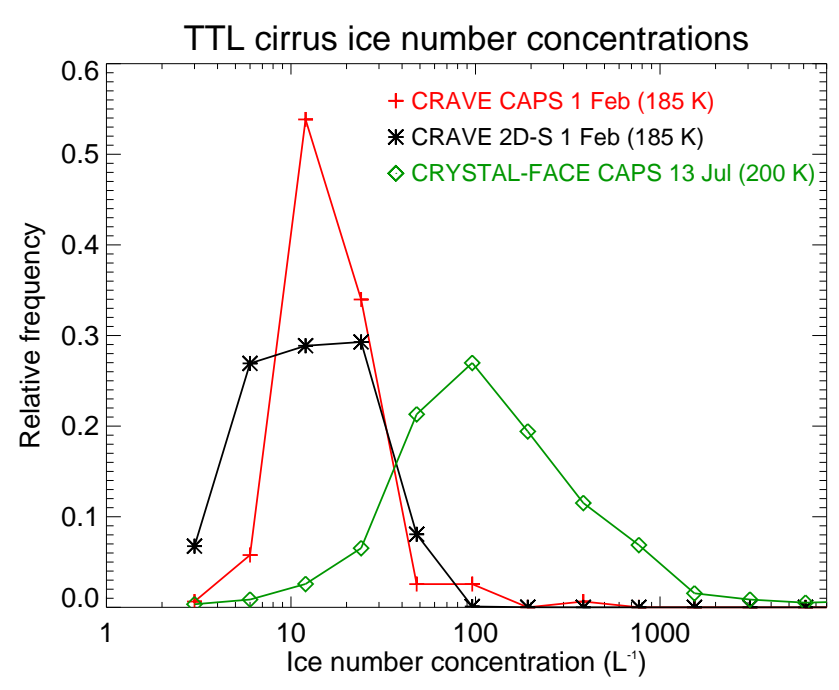

Fig. 7. Red and Black curves show ice concentration frequency distributions from CAPS and 2D-S measurements, respectively, in very cold TTL cirrus sampled during the CRAVE mission. Ice concentrations in these clouds were almost exclusively less than $100 \mathrm{~L}^{-1}$. The green curve shows the ice concentration frequency distribution from a warmer tropopause cirrus layer sampled during CRYSTALFACE with larger ice concentrations predominating.

full vertical extents of the cloud layers to avoid a sampling bias. It should also be noted that analysis of back trajectories from the flight paths along with infrared satellite imagery showed that the air sampled had not been influenced by convection for at least two weeks, indicating that these clouds were formed in situ in the TTL (Jensen et al., 2008).

Earlier measurements of TTL cirrus ice concentrations are consistent with the CRAVE results. Total ice concentrations reported by McFarquhar et al. (2000) from the ASSP and 1DC probes ranged from 37 to $102 \mathrm{~L}^{-1}$. Krämer et al. (2009) reported that in cold $(T<205 \mathrm{~K})$ TTL cirrus not associated with convection sampled with the Geophysica, FSSP ice concentrations ranged from 5 to $200 \mathrm{~L}^{-1}$. The cumulative dataset of TTL cirrus in situ sampling includes measurements in the eastern Pacific, central Pacific, western Pacific and South America. The CRAVE measurements included many hours of cold TTL cirrus sampling on multiple flights. Aircraft measurements necessarily give limited sampling of the lifecycle and extent of cloud systems, and we cannot rule out the possibility that larger ice concentration were present in some parts of the clouds or earlier in the cloud lifecycles. However, the evidence from the available measurements at least suggests that ice concentrations larger than $100 \mathrm{~L}^{-1}$ rarely occur in these clouds.

For comparison, we have also included in Fig. 7 a frequency distribution of ice concentrations measured by CAPS in a warmer cirrus layer formed in situ near the subtropical tropopause (Jensen et al., 2005). The ice concentrations in 
this cloud were considerably larger than those in the cold TTL cirrus, with values often exceeding $100 \mathrm{~L}^{-1}$ and sometimes exceeding $1000 \mathrm{~L}^{-1}$. Both the low ice concentrations in the cold CRAVE TTL cirrus and the apparent decrease in ice concentration with decreasing temperature are in conflict with theoretical expectations for the conventional theory of ice nucleation by homogeneous freezing of aqueous aerosols (see Sect. 2).

Chepfer and Noel (2009) recently used CALIOP scattering ratios (ratios of the $532 \mathrm{~nm}$ backscatter to molecular backscatter), depolarization ratios, and color ratios (ratios of the $1064 \mathrm{~nm}$ and $532 \mathrm{~nm}$ backscatter ratios) to provide global information about the microphysical properties of clouds in the TTL. They concluded that a subset of the clouds that were depolarizing and had color ratios significantly less than unity were possibly Nitric Acid Trihydrate (NAT) particles. This conclusion is implausible because the nitric acid concentration in the TTL is far too low to produce NAT clouds detectable by CALIPSO (Jensen and Drdla, 2002; Poole et al., 2009). What the CALIOP measurements do suggest is that some fraction of TTL clouds are composed of small (a few microns or less), nonspherical particles. Such cloud microphysical properties are just what would be expected if homogeneous aerosol freezing were driven by rapid cooling caused by gravity waves. Hence, the CALIPSO measurements may indicate that there are locations in the TTL where homogeneous freezing is the dominant ice production process. Alternatively, these clouds with small ice crystals could be persistent small ice crystals detrained into the TTL by intense deep convection. Caution must be taken when interpreting the CALIOP color ratios because the $1064 \mathrm{~nm}$ channel is essentially calibrated by assuming that anvil cirrus have a color ratio of unity (Reagan et al., 2002).

\subsection{Ice crystal size distributions}

The TTL cirrus measurements listed in Table 1 also provide useful information about ice crystal size distributions in these clouds. Lawson et al. (2008) presented average size distributions from several hours of in situ TTL cirrus sampling during the CRAVE mission. The average size distribution is very broad, with crystal maximum dimensions ranging from $\simeq 2 \mu \mathrm{m}$ to about $100 \mu \mathrm{m}$. Davis et al. (2010) showed that size distributions measured in TTL cirrus from several other field experiments were remarkably consistent with the CRAVE measurements. All of the measurements indicated very broad distributions. It seems reasonable to assume that the breadth of the distribution is a result of averaging over the vertical and horizontal extents of the clouds. Here, we show that even within limited altitude ranges, the cloud size distributions are broad.

Figure 8 shows 2D-S and CAPS size distributions from two different flights segregated into altitude ranges in the clouds. The comparison between CAPS and 2D-S is reasonable, although there are significant differences. 2D-S in- dicates higher concentrations of crystals at sizes of approximately $10 \mu \mathrm{m}$ than CAPS. The dips in the CAPS size distributions at $\simeq 8 \mu \mathrm{m}$ and $20-30 \mu \mathrm{m}$ most likely are the result of mis-sizing of non-spherical crystals. Retrieval of size from the CAS is done using Mie scattering theory assuming spherical particles. Aspherical particles will be undersized with respect to spherical particle as was shown by Borrmann et al. (2000) who used T-matrix calculations to estimate the undersizing of spheroids as a function of aspect ratio for the FSSP300 , another optical particle counter with similar collection angles as the CAS. For example, they found that on average, spheroids with aspect ratios of 2 to 1 and diameters of $8 \mu \mathrm{m}$ and $20 \mu \mathrm{m}$, will be sized as 5 and $15 \mu \mathrm{m}$ spherical particles, respectively. The relative difference between the peaks and valleys will be sensitive to the magnitude of the asphericity as a function of size and the fraction of aspherical particle in each size category.

The expected gravitational size sorting is evident in the size distributions, particularly in the 2D-S distributions: larger crystals are most abundant in the lower parts of the clouds. However, the size distributions are broad throughout the vertical extent of the cloud, suggesting that vertical averaging is not responsible for the breadth of the distributions. These broad size distributions are difficult to reconcile from theoretical expectations assuming homogeneous freezing ice nucleation (see Section 2).

\section{TTL cirrus extinctions}

Cloud ice water content scales as $n r^{3}$, where $n$ is ice crystal concentration, and $r$ is a characteristic size, whereas extinction scales as $n r^{2}$. As a result, for a fixed ice water content, extinction will increase as ice concentration increases (and size correspondingly decreases). This dependence would seem to imply that if simulations using conventional microphysics (homogeneous freezing) substantially overestimate ice concentration, they will also overestimate cloud extinction. This line of reasoning led us to compare simulated cloud extinctions with the global CALIPSO measurements (see Sect. 2 for discussion of CALIPSO extinction measurement).

For a statistical comparison with measured TTL cirrus extinctions throughout the tropics, we use a detailed cloud model driven by meteorological analysis temperature and wind fields (Jensen and Pfister, 2004). 40-day back trajectories are run from 20 January 2007 on a $10^{\circ}$ longitude by $5^{\circ}$ latitude grid from $-30^{\circ}$ to $30^{\circ}$ latitude (648 trajectories). Temperature profiles from the analyses are extracted at each time point along the trajectories, resulting in temperature "curtains" versus time and height. The National Center for Environmental Prediction (NCEP) analyses used are known to have a warm bias of a few $\mathrm{K}$ at the tropical tropopause. We adjust the temperatures near the tropopause in a way that results in statistical agreement with radiosondes. In addition, 

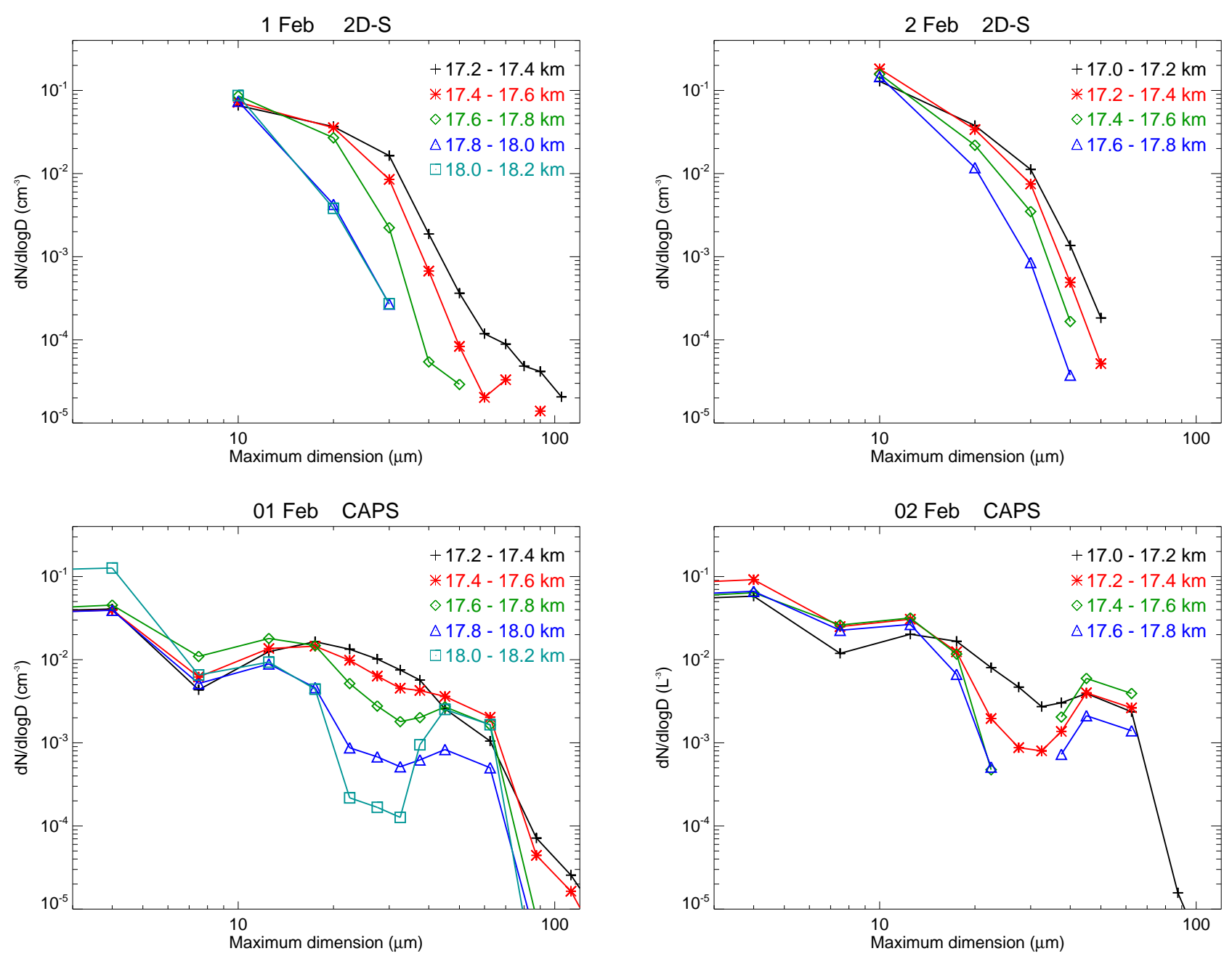

Fig. 8. 2D-S and CAPS size distributions from TTL cirrus layers sampled on 1 and 2 February 2006. The size distributions are broad throughout the clouds. See text for discussion.

the analyses are unable to resolve much of the wave activity in the tropopause region that is important for cloud microphysics. As described by Jensen and Pfister (2004), we superimpose temperature oscillations resulting from a spectrum of waves based on aircraft and ground-based observations.

These temperature curtains are used to drive the onedimensional cloud simulations. Nucleation of ice crystals is specified using the Koop et al. (2000) parameterization of aerosol homogeneous freezing rates, and the dependence on cooling rate and assumed aerosol size distribution is treated. The locations and heights of individual ice crystals are then tracked in a Lagrangian sense, such that there is no numerical diffusion associated with advection and deposition growth (as there would be if an Eulerian vertical grid and a bin microphysics scheme were used). Water vapor is treated on an Eulerian grid. Exchange between the vapor and ice phases is treated by summing up the deposition growth and/or sublimation of all ice crystals within each Eulerian grid box, and then changing the vapor concentration accordingly. Essentially, we are simulating cloud properties and water vapor in a vertical column of the atmosphere. Ascent rates along the temperature curtains are derived from radiative heating rate calculations including cloud distributions indicated by CALIPSO (Yang et al., 2009) The objective is to (at least statistically) represent the TTL cloud properties and water vapor fields.

Though only about $1 \%$ of convection actually reaches the TTL, convective turnover times are still short enough to be comparable to the time it takes air parcels to move upward through the TTL via the mean ascent as diagnosed by the (Yang et al., 2009) radiative heating calculation. Thus, some method of including the recurrent hydration due to convection must be included in our simulations. For this purpose, 
we use 3-hourly global geostationary infrared satellite imagery, global 3-hourly rainfall analyses derived from several polar orbiting satellites (Huffman et al., 2007), as well as CLOUDSAT and CALIPSO data to arrive at a method of evaluating the height of convection. As a first step, the trajectory curtains are "marched" through the 3-hourly global rainfall and IR satellite imagery to arrive at a convective cloud top temperature as a function of time along each trajectory curtain. Convection is defined by regions where rainfall is greater than $1 \mathrm{~mm} \mathrm{~h}^{-1}$, such that convective influence only occurs along those parts of the trajectory where rainfall exceeds that threshold. The altitude of that convection is defined by IR brightness temperatures, which are adjusted by $-6 \mathrm{~K}$ to reflect the fact that IR methods yield cloud tops that are about $1 \mathrm{~km}$ lower than actual lidar observations (Sherwood et al., 2003).

The cloud-top altitude and cloud-top potential temperature are derived by matching the evaluated cloud-top temperature with the vertical temperature profile at each time step. The temperature profile used in this step represents a mixture between an isentropic convective plume and the analysis temperature profile at the time of the convection. We use $360 \mathrm{~K}$ and $375 \mathrm{~K}$ isentropes for oceanic and continental convection, respectively. This scheme is similar to a scheme where cloud top temperatures are matched directly with analysis profiles except that cloud tops tend to be a bit lower. This result is consistent with observations that show that convection tends to lower the altitude of the cold point in a sounding (Selkirk, 1993). The CLOUDSAT deep convective cloud classification data and CALIPSO layer data are used to arrive at a vertical and horizontal distribution of convective cloud top altitudes for the winter season. This information is used to "calibrate" the adjustable parameters in the algorithm, the most important of which is the rainfall rate threshold. The overall seasonal cloud top distributions for the global tropics calculated using the above scheme compare well with the actual CLOUDSAT/CALIPSO distributions, both in altitude and geographically. Most notably, both the method and the data display a peak in the convective cloud top distribution at about $130 \mathrm{hPa}$.

Although we include the impact of convection on TTL humidity, we do not directly simulate anvil cirrus produced by deep convection. Therefore, for comparison with CALIOP measurements, we restrict ourselves to regions of the tropics where convection rarely reaches the altitude of interest and the vast majority of TTL cirrus is likely formed in situ (see Fig. 9). Since the TTL is often supersaturated with respect to ice (Jensen et al., 2001), cloud ice detrained from deep convection into the TTL may frequently be very persistent and spread into the non-convective regions we are focusing on. However, the convectively-generated cloud would, in general, have higher ice water content and extinction than cloud formed in situ in the dry TTL. As discussed below, the CALIOP extinctions are actually lower than the simulated in situ cloud extinctions based on conventional microphysics.

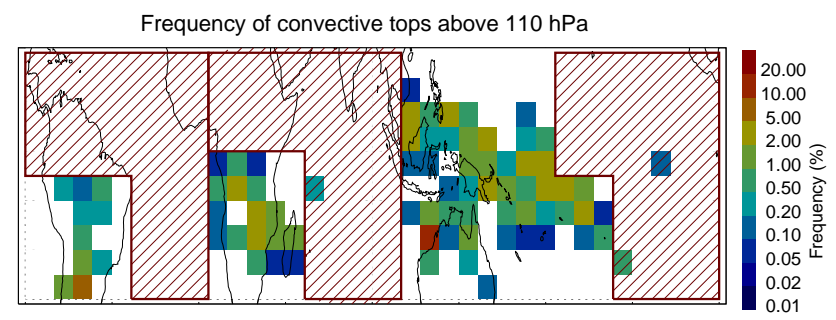

Fig. 9. Convective cloud occurrence frequencies calculated from geostationary satellite infrared imagery with adjustments made for the known high bias in cloud-top brightness temperatures (see text for details). The time period covered is 1-20 January 2007, corresponding to the simulated time period. For comparison between simulated cloud extinctions and CALIPSO measurements, we focus on the regions (indicated by the red cross-hatched regions) that are essentially free of convective clouds in the upper TTL.

Therefore, contamination from aged TTL anvil cirrus will not likely change our conclusions.

CALIPSO measurements generally indicate that cloud occurrence is quite widespread in the tropics during Boreal winter at altitudes of $\simeq 16-17 \mathrm{~km}$ (Fu et al., 2007). In order to ensure that the convection-free regions we have chosen are not devoid of in situ cloud formation, we examine the regional distribution of TTL cloud frequencies for 1-20 January 2007 determined from CALIPSO. Cloud frequencies were calculated using the CALIPSO Level $25-\mathrm{km}$ cloud layer files (Anselmo et al., 2007). We count the cloud occurrence if the cloud-top pressure indicated by CALIOP is less than the pressure level of interest $(80$ or $100 \mathrm{hPa})$ and the cloud-base pressure is greater than the particular pressure level. We also restrict ourselves to vertically thin clouds (cloud depths less than $50 \mathrm{hPa}$ ). The resulting cloud frequencies are shown in Fig. 10. The highest cloud occurrence frequencies are generally in the regions we have chosen to exclude to avoid convective clouds, partly because the cold tropopause regions in the tropics tend to be co-located with convective regions. However, cloud occurrence is still significant (frequencies up to $\simeq 50 \%$ at $100 \mathrm{hPa}$ and $10 \%$ at $80 \mathrm{hPa}$ ) in the regions we are focusing on.

A comparison between the frequency distributions of CALIOP cloud extinctions and simulated cloud extinctions in the geographic regions identified as devoid of convective clouds is shown in Fig. 11. The CALIOP extinction frequency distribution peaks at values of $\simeq 0.01-0.02 \mathrm{~km}^{-1}$, corresponding to zenith optical depths of $0.01-0.02$ for a 1$\mathrm{km}$ thick cloud. These clouds are likely subvisible to ground observers. At extinctions below the peak at $0.01-0.02 \mathrm{~km}^{-1}$, the decreased sensitivity of the CALIOP measurements to decreasing cloud extinction probably contributes to the dropoff in the frequency distribution. The CALIOP extinctions are consistent with the TTL cirrus in situ observations 
CALIOP cloud frequency (Jan, 2007)
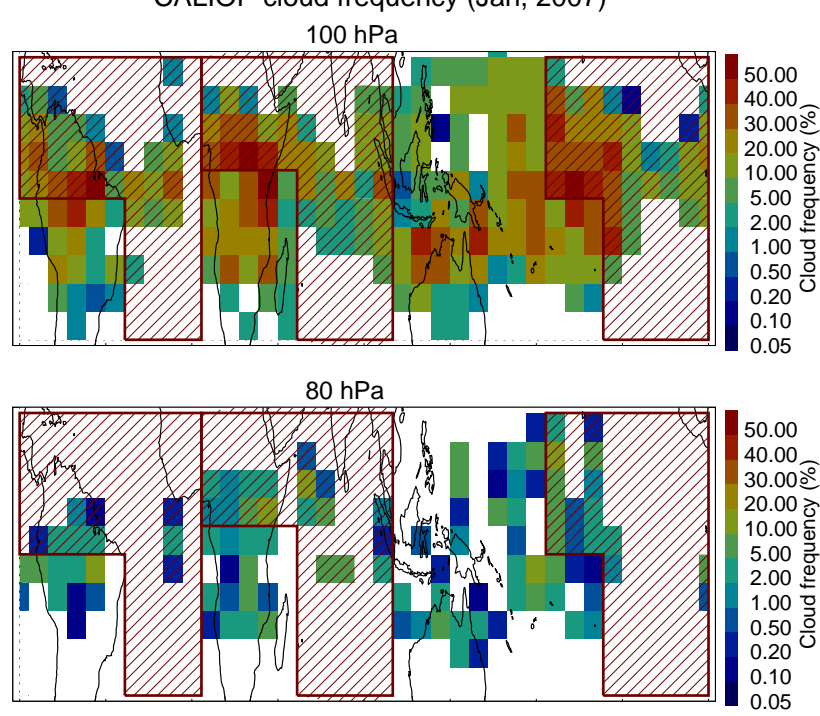

Fig. 10. Frequency of clouds detected by CALIOP at $100 \mathrm{hPa}$ (top) and $80 \mathrm{hPa}$ (bottom). We restrict ourselves to relatively thin (less than $50 \mathrm{hPa}$ depth) clouds. The regions we have chosen (indicated by the red cross-hatched regions) to avoid deep convection still contain substantial cloud occurrence in the TTL.

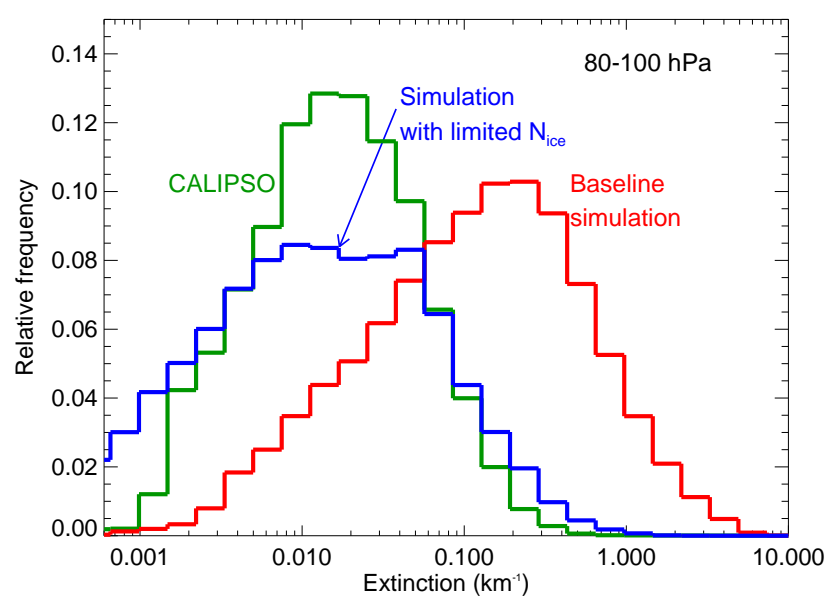

Fig. 11. Frequency distributions of cloud extinctions measured by CALIOP (green), derived from the baseline simulation using homogeneous freezing (red), and derived from a heterogeneous nucleation simulation resulting in low ice concentrations (blue). Consistent with the excessive ice concentrations produced by homogeneous freezing, the simulated extinctions exceed those indicated by CALIOP measurements.

from CRAVE. Lawson et al. (2008) reported mean and maximum extinctions of 0.009 and $0.063 \mathrm{~km}^{-1}$, respectively.

As anticipated from the discussion above, the TTL cirrus simulations using conventional microphysics (homogeneous freezing) produced considerably higher extinctions than those measured by CALIOP (Fig. 11). The peak in the simulated extinction frequency distribution occurs at about an order of magnitude higher extinction than does the measured extinction frequency distribution. If we instead use a heterogeneous nucleation scenario that limits the concentration of ice crystals to values comparable to the in situ measurements, then the simulated extinction frequency distribution shows much better agreement with the observations (blue curve in Fig. 11).

\section{Potential TTL ice nuclei}

The measurements presented here seem to be in conflict with theoretical predictions based on the typical assumption that ice nucleation is dominated by homogeneous freezing of aqueous aerosols and that all aerosols freeze at approximately the same ice supersaturation. There are a number of possible physical processes that can lead to lower ice concentrations than simple calculations of homogeneous freezing in parcel models or one-dimensional models predict. The coexistence of cubic ice and hexagonal ice (which is likely at low TTL temperatures) can lead to a Bergeron effect whereby the vapor is transferred to the phase with lower vapor pressure (hexagonal ice), and the cubic ice particles sublimate (Murphy, 2003). Spichtinger and Gierens (2009) showed that, under some conditions, small-scale dynamical variability can lead to patches of cloud with low ice concentration. These low-concentration patches will spread downward via sedimentation, potentially quenching supersaturation at lower altitudes and resulting in a cloud that has low ice concentration through much of its depth. Durran et al. (2009) recently showed that radiative heating in TTL cirrus will drive both vertical motions within the clouds and waves propagating away from the clouds. Additional cloud-resolving model simulatioins with detailed microphysics would be helpful to investigate the impact of these radiatively-driven motions on cloud microphysics. Stochastic condensation is another process that could affect both ice concentrations and size distributions. It is possible that the composition of aqueous TTL aerosols results in a significant spread in the supersaturation threshold for homogeneous freezing such that some subset of the aerosols can nucleate ice at a relatively low supersaturation, and growth of these crystals can quench further nucleation. Examination of these (and other) possibilities is the subject of a follow-on study.

Perhaps the most obvious mechanism for limiting ice concentrations is nucleation on a subset of the aerosols that are effective heterogeneous ice nuclei (IN). Gensch et al. (2008) showed that by including $100 \mathrm{~L}^{-1} \mathrm{IN}$ in a simulation of TTL cirrus observed during CRAVE, they could produce reasonable agreement with the observed ice concentrations. Limited information is available about TTL aerosol composition in general, and TTL IN properties are even less well constrained. The bulk of the information about TTL aerosol 
composition comes from the Particle Analysis by Laser Mass Spectrometry (PALMS) instrument deployed on the WB-57 in recent tropical campaigns (Froyd et al., 2009). Multiple field and laboratory studies have shown that mineral dust particles are relatively effective IN (e.g. Archuleta et al., 2005; Möhler et al., 2006). However, relatively few $\left(\simeq 5 \mathrm{~L}^{-1}\right) \mathrm{min}$ eral dust particles were detected in the PALMS TTL measurements; these concentrations are well below the observed ice concentrations reported above. Most of the aerosols present were neutralized sulfate internally mixed with organic material.

PALMS measurements during CRAVE also included time periods in clouds when a Counterflow Virtual Impact (CVI) was used to reject interstitial aerosols and only permit ice crystals to enter the inlet. The sample stream was subsequently heated such that the composition of residual aerosols from the ice crystals (presumably the ice nuclei) was measured by PALMS. (Froyd et al., 2010a) described the results from this analysis. Surprisingly, mineral dust does not appear to be enhanced in the PALMS TTL ice crystal residual measurements relative to the ambient aerosol population. Almost every particle that formed ice was an internal mixture of neutralized sulfate and organic carbon. In general, the ice crystal residuals were not distinct in terms ov organic/sulfate mass ratio, oxidized organic content, sulfate acidity, nitrogen content, or size compared to the aerosol population in general, suggesting that ice crystals are not nucleating on a subset of the aerosol population that has a particularly unusual composition (Froyd et al., 2010a).

At the cold TTL temperatures where liquid water will not exist, the two most likely modes of heterogeneous ice nucleation are direct deposition from the vapor phase onto solid particles and heterogeneous freezing in aqueous aerosols with insoluble components. Recent laboratory studies have suggested that solid ammonium sulfate particles could be effective deposition IN, promoting ice nucleation at relatively low ice supersaturations (Wise et al., 2009; Abbatt et al., 2006; Baustian et al., 2009). It should be noted that these laboratory studies suggest that only a small fraction (probably less than 1 in 1000) of the crystalline sulfate particles act as IN. Further, there is no knowledge of how the freezing fraction depends on ammonium sulfate particle size; it is possible that only supermicron particles were active in the laboratory experiment, and such large particles would be very rare in the TTL. Further laboratory work is required to determine whether ammonium sulfate particles (and mixedcomposition particles) are effective IN under atmospherically relevant conditions.

Ammonium sulfate will effloresce if the relative humidity with respect to liquid water (RH) drops below about $35 \%$, whereas deliquescence occurs at $\mathrm{RH} \simeq 80 \%$. If air is detrained from convection (with $\mathrm{RHI}=100 \%$ ) in the middle troposphere, where temperatures are relatively warm, it is unlikely the air will subsequently dry out enough to permit $\left(\mathrm{NH}_{4}\right)_{2} \mathrm{SO}_{4}$ efflorescence unless considerable decent occurs.
Further, at temperatures not far below $0{ }^{\circ} \mathrm{C}$, the difference between ice and liquid $\mathrm{H}_{2} \mathrm{O}$ vapor pressures is sufficiently small such that even if the $\mathrm{RH}$ had previously decreased enough to promote efflorescence, deliquescence could occur as the RH subsequently increased before ice supersaturation gets large enough to promote heterogeneous freezing on dry ammonium sulfate particles. However, at the very cold tropical tropopause low RH values are possible even if the RHI is relatively high. (e.g., at $190 \mathrm{~K}, \mathrm{RHI}=70 \%$ corresponds to $\mathrm{RH}=35 \%$.) Air parcels detrained from deep convection at $190 \mathrm{~K}$ with $\mathrm{RHI}=100 \%$ need only warm up about $2.2 \mathrm{~K}$ before the $\mathrm{RH}$ will drop to $35 \%$, permitting $\left(\mathrm{NH}_{4}\right)_{2} \mathrm{SO}_{4}$ efflorescence. If the air parcel subsequently cools off, the RHI will exceed $160 \%$ before the RH reaches $80 \%$ where deliquescence would occur. Hence, heterogeneous freezing on some as yet undetermined fraction of solid ammonium sulfate particles could easily occur before deliquescence in the cold uppermost tropical troposphere.

As discussed above, PALMS measurements of TTL aerosol composition do indicate that the aerosols are largely neutralized (Froyd et al., 2009). However, nearly all of the aerosols are mixtures of sulfates and organics. Mixtures of sulfates and organics could have lower efflorescence relative humidities than pure ammonium sulfate, but Takahama et al. (2007) showed that organic coatings do not significantly shift the efflorescence RH, at least at room temperature. In addition, the organic material could reduce the effectiveness of ammonium sulfate particles as ice nuclei (Möhler et al., 2008).

As a means of quantifying the likelihood of ammonium sulfate particles in the TTL being solid, we use the trajectory curtains and convective influence calculations described in Sect. 5. We track air parcels after they exit from deep convective systems and experience temperature variations. We assume that upon exiting the convective systems, the aerosols are aqueous ammonium sulfate, and the RHI is $100 \%$. This assumption, along with the temperature at the location of convective injection, sets the water vapor concentration in the parcel. As described above, we use the heating rate calculations of (Yang et al., 2009) (including clouds based on CALIPSO measurements) to calculate parcel ascent rates along the trajectories assuming radiative heating is balanced by adiabatic ascent. If the parcel RH drops below 35\%, we assume that efflorescence occurs, and the ammonium sulfate particles remain solid unless the RH exceeds the deliquescence point $(\mathrm{RH} \simeq 80 \%)$.

An example of the temperature, RH, RHI, and ammonium sulfate phase for a typical parcel is shown in Fig. 12. For this example, convective injection occurred at a potential temperature of $373.7 \mathrm{~K}$ where the temperature was $193.7 \mathrm{~K}$. The parcel water vapor concentration was set such that the RHI was $100 \%$, with a corresponding RH of $\simeq 41 \%$. When the parcel warmed up to $196.1 \mathrm{~K}$, the RH dropped below $35 \%$, and $\left(\mathrm{NH}_{4}\right)_{2} \mathrm{SO}_{4}$ efflorescence occurred. Since the RH did not rise above $80 \%$ for the remainder of the parcel trajectory, 


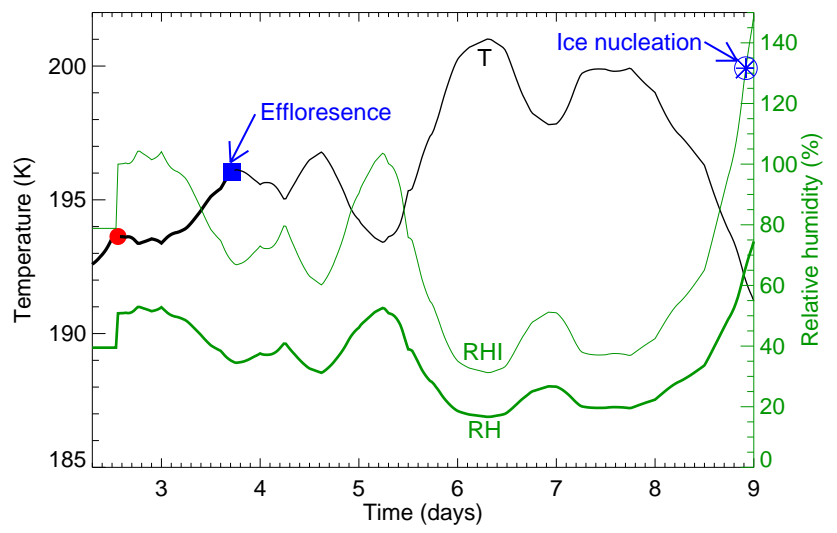

Fig. 12. Time series of temperature (black), RH (thick green), and RHI (thin green) for a typical parcel on its path upward through the TTL. At the time of exit from deep convection (red circle), the RHI is set to $100 \%$. After the temperature warms up $\simeq 2 \mathrm{~K}$, the RH drops below $35 \%$, at which point ammonium sulfate particles would effloresce (blue square). The RH subsequently remains below $80 \%$, and the ammonium sulfate particles in this parcel would have remained solid for at least a couple of weeks. Because of the low temperature, when the parcel cools the RHI can rise well above $100 \%$ while the $\mathrm{RH}$ remains below $80 \%$. If the threshold RHI for deposition nucleation on the $\left(\mathrm{NH}_{4}\right)_{2} \mathrm{SO}_{4}$ particles was about $130 \%$, then ice nucleation could occur near the end of the time series shown (blue asterisk) while $\mathrm{RH}$ was still below $80 \%$ and the ammonium sulfate particles were still dry.

the ammonium sulfate particles would have remained solid. Near the end of the time series shown, the temperature drops, and RHI increases well above $100 \%$. If the threshold RHI for deposition nucleation on the ammonium sulfate particles were below about $150 \%$, then ice nucleation would occur before the $\mathrm{RH}$ exceeded $80 \%$, and the $\left(\mathrm{NH}_{4}\right)_{2} \mathrm{SO}_{4}$ particles would still be dry.

We use the entire set of 648 trajectory curtains described above to generate statistics of ammonium sulfate phase in the TTL. For each trajectory curtain, parcels are launched from 30 potential temperature levels $(355-385 \mathrm{~K}$, every $1 \mathrm{~K}$ ) at the beginning of the 40-day trajectory. We begin keeping track of the ammonium sulfate phase after a parcel has encountered a convective injection event, using the procedure described above. The time periods during which ammonium sulfate particles are wet or dry along the parcel trajectories are summed up in potential temperature bins. Only times when the trajectories are within $\pm 20^{\circ}$ latitude are included. The resulting fraction of time that ammonium sulfate particles would be expected to be dry is shown as a function of height (potential temperature) in Fig. 13. The average temperature profile versus height is also shown. In the lower TTL (below $\simeq 365 \mathrm{~K}$ ), where temperatures are relatively high and convective encounters are relatively frequent, ammonium sulfate particles are likely in the aqueous phase most

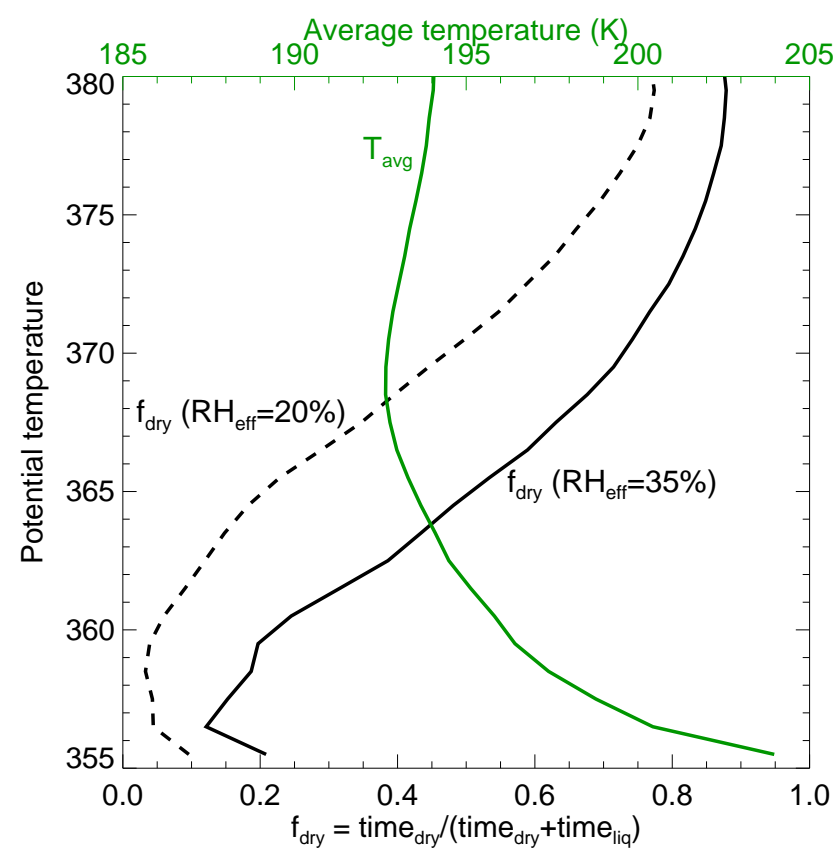

Fig. 13. Height profiles of the fraction of time that ammonium sulfate particles are expected to be dry (rather than in the aqueous phase) and mean temperature. Calculations are based on parcel trajectory temperature histories following convective injection events. See text for details.

of the time. However, at and above the cold point, parcels often encounter RH below the efflorescence point, and the parcels almost never get humid enough for subsequent deliquescence. The dashed curve in Fig. 13 shows the fraction of time that particles with an efflorescence point of $\mathrm{RH}=20 \%$ would be dry. These calculations suggest that in the upper TTL, ammonium sulfate particles (or even mixed ammonium sulfate/organic particles) could often be dry and potentially available for deposition nucleation.

Another potentially important consideration is the process known as "preactivation", whereby particles that had previously been involved in ice nucleation could subsequently be more effective IN than particles with the same composition that had not previously acted as IN (e.g. Roberts and Hallett, 1968). Although the physical process involved with preactivation is not clear, Roberts and Hallett (1968) estimated a lower RHI limit of $50 \%$ for survival of preactivated IN. As mentioned above, convective-influence analyses (trajectories tracing the airmasses sampled back to where they last encountered convection) indicate that the TTL cirrus air sampled during the CRAVE mission had not encountered deep convective outflow during the previous two weeks (Froyd et al., 2009). Back trajectories indicate that maximum temperatures experienced by the air sampled during the previous two weeks were about $5-15 \mathrm{~K}$ warmer than the temperatures during the TTL cirrus sampling. Assuming the air was 
saturated with respect to ice during the cloud sampling, the preactivated IN would have to needed to survive periods with RHI of $8-42 \%$. Therefore, it seems unlikely that preactivated IN dominated the ice nucleation in these clouds.

\section{Implications of heterogeneous nucleation for cloud processes}

The primary implications of the predominance of either heterogeneous nucleation on a small subset of the available aerosols or homogeneous freezing of aqueous aerosols (with all aqueous aerosols freezing at approximately the same supersaturation) for cloud properties are the ice concentrations and sizes. Homogeneous nucleation produces large concentrations of relatively small crystals; rapid cooling driven by gravity waves often present in the TTL region result in even higher concentrations of ice crystals produced by homogeneous freezing. In contrast, heterogeneous nucleation could potentially produce relatively low concentrations of ice crystals that can grow to relatively large sizes. Here, we discuss the implications of the very different ice crystal size distributions produced by homogeneous and heterogeneous nucleation.

Given the optically thin nature of these clouds and their location near the tropical tropopause, the combination of solar and infrared absorption will result in net radiative heating throughout the cloud layers. For typical optical depths near the visibility limit $(0.03)$, the radiative heating rate will be on the order of a few K day ${ }^{-1}$ (Jensen et al., 1996; Comstock et al., 2002). It has been hypothesized that this radiative heating will predominantly result in lofting of the cloud layers (rather than local temperature change) (Ackerman et al., 1988). Corti et al. (2006) recently showed that cloud radiative heating can balance much of the adiabatic cooling driven by upward motion through the tropical upper troposphere. If optically thin TTL cirrus were lofted, the radiatively-driven ascent rate will be on the order of $0.5 \mathrm{~mm} \mathrm{~s}^{-1}$.

Even if the cloud radiative heating does drive vertical motion, the question of whether the cloud itself rises depends on the balance between the ascent rate and crystal sedimentation rates. If the clouds are produced by homogeneous freezing with gravity wave driven cooling, competition for vapor amongst the numerous crystals can limit their size to no more than a few $\mu \mathrm{m}$. The fallspeeds of such small crystals would be comparable to or perhaps somewhat smaller than the radiatively-driven ascent rates of $\simeq 0.5 \mathrm{~mm} \mathrm{~s}^{-1}$. However, the in situ measurements indicate that the most of the ice mass in these clouds is in crystals larger than a few $\mu \mathrm{m}$. Figure 14 shows the ice crystal size distribution from the tropopause layer cirrus sampled on 1 February during CRAVE along with the ice crystal terminal velocity as a function of crystal size. The corresponding mass-weighted fallspeed $\left(2.2 \mathrm{~cm} \mathrm{~s}^{-1} \approx 2 \mathrm{~km} \mathrm{day}^{-1}\right)$ is considerably larger than the radiatively driven lofting speed. Hence, the net motion

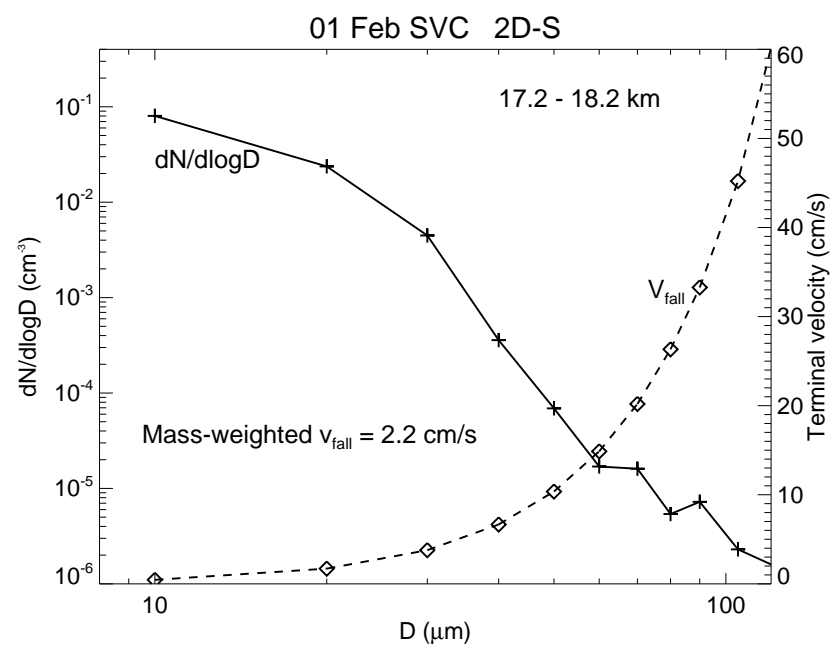

Fig. 14. The 2D-S ice crystal size distribution from the TTL cloud sampled on 1 February, 2006 and the ice crystal terminal velocity versus crystal diameter are shown. Given the relatively broad size distribution, the mass weighted fallspeed $\left(2.2 \mathrm{~cm} \mathrm{~s}^{-1}\right)$ is considerably larger than radiatively-driven upward motion in the cloud.

of these clouds will be downward. Even though the clouds themselves are moving downward, they can still act as agents of upward tracer transport.

If heterogeneous nucleation does dominate ice production near the cold tropical tropopause, then the frequencies, microphysical properties, radiative effects, and effects on stratospheric humidity of TTL cirrus will not be controlled predominantly by cooling rate, as would be the case if homogeneous nucleation dominated. Instead, the cloud properties and effects will depend on details of the composition of the TTL aerosol population In particular, the abundance of aerosols that happen to have compositions that make them effective IN will be important. If the effective IN are associated with human-related activities such as biomass burning, then anthropogenic aerosol emissions could control TTL cirrus properties. Presumably, the source of such particles to the uppermost tropical troposphere is deep convection. After an air parcel is detrained from deep convection, it will move slowly upward through the TTL and likely encounter multiple cloud formation events. In each of these cloud events, the most effective IN will form ice and be removed from the parcel by sedimentation. Therefore, it seems likely that the IN abundance and the properties of cirrus formed in the TTL will vary with the age of air since it was detrained from convection.

\section{Conclusions}

Consistent with past modeling studies, we have shown that the theory for homogeneous freezing of aqueous aerosols 
(the mechanism typically assumed to dominate ice formation in the upper troposphere) predicts relatively high ice concentrations for the cold environment near the tropical tropopause. In particular, the nearly ubiquitous temperature variability driven by gravity waves in this region should produce ice concentrations often exceeding $1000 \mathrm{~L}^{-1}$. The sudden production of numerous ice crystals should result in clouds with narrow ice crystal size distributions and crystal diameters less than about $20 \mu \mathrm{m}$.

The microphysical properties of thin cirrus formed near the tropical tropopause measured in recent high-altitude aircraft campaigns (including extensive sampling of these clouds) are in conflict with these theoretical expectations. Measured ice concentrations are frequently less than $50 \mathrm{~L}^{-1}$ and rarely exceed $100 \mathrm{~L}^{-1}$. Ice crystal size distributions are very broad even when the measurements are segregated into different altitude ranges, and relatively large crystals (maximum dimensions exceeding $50 \mu \mathrm{m}$ ) exist through much of the depth of the clouds.

If theoretical predictions based on homogeneous freezing nucleation theory give excessive ice concentrations they should also produce clouds with excessive extinctions (assuming cloud ice water content is not substantially under predicted by the theory). Consistent with the discrepancy between simulated and measured ice concentrations, we find that simulations of TTL thin cirrus throughout the tropics produce cloud extinctions that are statistically much higher than those measured by CALIPSO (Fig. 11). By limiting the concentration of ice crystals in the simulations, we get much better agreement with the measured extinctions than in the simulations using homogeneous freezing to predict ice concentrations.

There are a range of possible physical mechanisms that might limit ice concentrations in TTL cirrus, some involving interactions between cloud dynamics, ice sedimentation, and ice nucleation. Evaluation of these mechanisms is the subject of a follow-on study. We discuss here the possibility that a subset of the aerosols act as effective ice nuclei, thereby limiting the ice concentrations. We show that, given temperature variations indicated by trajectories, ammonium sulfate particles in the cold tropopause region will likely effloresce and subsequently remain in the solid phase. Since solid ammonium sulfate has been shown to be an effective ice nucleus in laboratory experiments, we suggest that these particles are a potential candidate as important IN for TTL cirrus formation. Considerable additional research is needed to determine whether solid ammonium sulfate particles are actually important for TTL cirrus nucleation, including laboratory studies with appropriate particle sizes and compositions, and field measurement that determine both particle composition and phase.

Sorting out the predominant ice nucleation mechanisms in TTL cirrus, as well as the composition of aerosols on which ice crystals typically nucleate, is important. The nucleation mechanisms have implications for TTL cirrus microphysical properties and what factors (i.e., dynamics or aerosol composition) control TTL cirrus properties and effects. In addition, nucleation on a special subset of the total aerosol population raises the possibility of significant anthropogenic influences on TTL cirrus.

Acknowledgements. We thank Qiang $\mathrm{Fu}$ and Qiong Yang for providing the tropical tropopause layer heating rates used in this work. We also than Mark Vaughan and Charles Trepte for helpful discussions. This work was supported by NASA's Radiation Science Program.

Edited by: M. Petters

\section{References}

Abbatt, J. P. D., Benz, S., Cziczo, D. J., Kanji, Z., Lohmann, U., and Möhler, O.: Solid ammonium sulfate aerosols as ice nuclei: A pathway for cirrus formation, Science, 313, 1770-1773, 2006.

Ackerman, T. P., Liou, K. N., Valero, F. P., and Pfister, L.: Heating rates in tropical anvils, J. Atmos. Sci., 45, 1606-1623, 1988.

Anselmo, T., Clifton, R., Hunt, W., Lee, K.-P., Murray, T., Powell, K., Rodier, S. D., Vaughan, M., Chometter, O., Viollier, M., Hagolle, O., Lifermann, A., Garnier, A., Pelon, J., Currey, J. C., Pitts, M., and Winker, D.: Cloud-Aerosol Lidar Infrared Pathfinder Satellite Observations Data Management System Data Products Catalog, PC-SCI-503, 2007.

Archuleta, C. M., DeMott, P. J., and Kreidenweis, S. M.: Ice nucleation by surrogates for atmospheric mineral dust and mineral dust/sulfate particles at cirrus temperatures, Atmos. Chem. Phys., 5, 2617-2634, 2005, http://www.atmos-chem-phys.net/5/2617/2005/.

Bacmeister, J. T., Eckermann, S. D., Newman, P. A., Lait, L., Chan, K. R., Loewenstein, M., Proffitt, M. H., and Gary, B.: Stratospheric horizontal wavenumber spectra of winds, potential temperature, and atmospheric tracers observed by high altitude aircraft, J. Geophys. Res., 101, 9441-9470, 1996.

Baker, B., Mo, Q., Lawson, R. P., Korolev, A., and O'Connor, D.: Drop size distributions and the lack of small drops in RICO rain shafts, J. Atmos. Sci., 1, in press, 2009.

Baumgardner, D., Jonsson, H., Dawson, W., Connor, D. O., and Newton, R.: The cloud, aerosol and precipitation spectrometer (CAPS): A new instrument for cloud investigations, Atmos. Res., 59, 59-60, 2001.

Baustian, K. J., Wise, M. E., and Tolbert, M. A.: Depositional ice nucleation on solid ammonium sulfate and glutaric acid particles, Atmos. Chem. Phys. Discuss., 9, 20949-20977, 2009, http://www.atmos-chem-phys-discuss.net/9/20949/2009/.

Borrmann, S., Luo, B., and Mischenko, M.: Application of the T-matrix method to the measurement of aspherical (ellipsoidal) particles with forward scattering optical particle counters, J. Aerosol. Sci., 31, 789-799, 2000.

Brock, C. A., Hamill, P., Wilson, J. C., Jonsson, H. H., and Chan, K. R.: Particle formation in the upper tropical troposphere: A source of nuclei for the stratospheric aerosol, Science, 270, 1650-1653, 1995.

Chepfer, H. and Noel, V.: A tropical "NAT-like" belt observed from space, Geophys. Res. Lett., 36, L03813, doi:10.1029/2008GL036289, 2009. 
Comstock, J. M., Ackerman, T. P., and Mace, G. G.: Ground based remote sensing of tropical cirrus clouds at Nauru Island: Cloud statistics and radiative impacts, J. Geophys. Res., 107(D23), 4714, doi:10.1029/2002JD002203, 2002.

Corti, T., Luo, B. P., Fu, Q., Vömel, H., and Peter, T.: The impact of cirrus clouds on tropical troposphere-to-stratosphere transport, Atmos. Chem. Phys., 6, 2539-2547, 2006, http://www.atmos-chem-phys.net/6/2539/2006/.

Davis, S. M., Hlavka, D., Jensen, E., Rosenlof, K., Schmidt, S., Borrmann, S., Frey, W., Lawson, P., Vömel, H., and Bui, T.-P.: In situ and lidar observations of subvisible cirrus clouds during TC4, J. Geophys. Res., submitted, 2010.

Denning, R. F., Guidero, S. L., Parks, G. S., and Gary, B. L.: Instrument description of the airborne microwave temperature profiler, J. Geophys. Res., 94, 16757-16765, 1989.

Durran, D. R., Dinh, T., Ammerman, M., and Ackerman, T.: The mesoscale dynamics in thin tropical tropopause cirrus, J. Atmos. Sci., 66, 2859-2873, 2009.

Field, P. R., Wood, R., Brown, P. R. A., Kaye, P. H., Hirst, E., and Greeaway, R.: Ice particle interarrival times measured with a fast FSSP, J. Atmos. Ocean. Tech., 20, 249-261, 2003.

Field, P. R., Heymsfield, A. J., and Bansemer, A.: Shattering and particle interarrival times measured by optical array probes in ice clouds, J. Atmos. Ocean. Tech., 23, 1357-1371, 2006.

Fritts, D. C. and Nastrom, G. D.: Sources of mesoscale variability of gravity waves. Part II: Frontal convective, and jet stream excitation, J. Atmos. Sci., 49, 111-127, 1992.

Froyd, K. D., Murphy, D. M., Sanford, T. J., Thomson, D. S., Wilson, J. C., Pfister, L., and Lait, L.: Aerosol composition of the tropical upper troposphere, Atmos. Chem. Phys., 9, 4363-4385, 2009, http://www.atmos-chem-phys.net/9/4363/2009/.

Froyd, K. D., Murphy, D. M., Lawson, P., Baumgardner, D., and Herman, R. L.: Aerosols that form subvisible cirrus at the tropical tropopause, Atmos. Chem. Phys., 10, 209-218, 2010, http://www.atmos-chem-phys.net/10/209/2010/.

Fu, Q., Hu, Y., and Yang, Q.: Identifying the top of the tropical tropopause layer from vertical mass flux analysis and CALIPSO lidar cloud observations, Geophys. Res. Lett., 34, L14813, doi:10.1029/2007GL030099, 2007.

Fueglistaler, S., Bonazzola, M., Haynes, P. H., and Peter, T.: Stratospheric water vapor predicted from the Lagrangian temperature history of air entering the stratosphere in the tropics, J. Geophys. Res., 110, D08107, doi:10.1029/2004JD005516, 2005.

Fueglistaler, S., Dessler, A. E., Dunkerton, T. J., Folkins, I., Fu, Q., and Mote, P. W.: The tropical tropopause layer, Rev. Geophys., 110, doi:10.1029/2004JD005516, 2008.

Gensch, I. V., Bunz, H., Baumgardner, D. G., Christensen, L. E., Fahey, D. W., Herman, R. L., Popp, P. J., Smith, J. B., Troy, R. F., Webster, C. R., Weinstock, E. M., Wilson, J. C., Peter, T., and Krämer, M.: Supersaturations, microphysics and nitric acid partitioning in a cold cirrus cloud observed during CR-AVE 2006: an observation-modelling intercomparison study, Environ. Res. Lett., 3, 1-9, 2008.

Gettelman, A., Randel, W. J., Wu, F., and Massie, S. T.: Transport of water vapor in the tropical tropopause layer, Geophys. Res. Lett., 29, 1009, doi:10.1029/2001GL013818, 2002.

Heymsfield, A. J.: Ice particles observed in a cirroform cloud at $85^{\circ} \mathrm{C}$ and implications for polar stratospheric clouds, J. Atmos. Sci., 43, 851-855, 1986.
Heymsfield, A. J.: On measurements of small ice particles in clouds, Geophys. Res. Lett., 34, L23812, doi:10.1029/2007GL030951, 2007.

Huffman, G. J., Adler, R. F., Bolvin, D. T., Gu, G., Nelkin, E. J., Bowman, K. P., Hong, Y., Stocker, E. F., and Wolff, D. B.: The TRMM Multi-satellite Precipitation Analysis: Quasi-global, multi-year, combined-sensor precipitation estimates at fine scale, J. Hydrometeor., 8, 38-55, 2007.

Jensen, E. J. and Drdla, K.: Nitric acid concentrations near the tropical tropopause: Implications for the properties of tropical nitric acid trihydrate clouds, Geophys. Res. Lett., 29, 2001, doi:10.1029/2002GL015190, 2002.

Jensen, E. J. and Pfister, L.: Transport and freeze-drying in the tropical tropopause layer, J. Geophys. Res., 109, D02207, doi:10.1029/2003JD004022, 2004.

Jensen, E. J. and Toon, O. B.: Ice nucleation in the upper troposphere: Sensitivity to aerosol number density, temperature, and cooling rate, Geophys. Res. Lett., 21, 2019-2022, 1994.

Jensen, E. J., Toon, O. B., Selkirk, H. B., Spinhirne, J. D., and Schoeberl, M. R.: On the formation and persistence of subvisible cirrus clouds near the tropical tropopause, J. Geophys. Res., 101, 21361-21375, 1996.

Jensen, E. J., Pfister, L., Ackerman, A. S., and Tabazadeh, A.: A conceptual model of the dehydration of air due to freeze-drying by optically thin, laminar cirrus rising slowly across the tropical tropopause, J. Geophys. Res., 106, 17273-17252, 2001.

Jensen, E. J., Pfister, L., Bui, T.-P., Weinheimer, A., Weinstock, E., Smith, J., Pittmann, J., Baumgardner, D., and McGill, M. J.: Formation of a Tropopause Cirrus Layer Observed over Florida during CRYSTAL-FACE, J. Geophys. Res., 110, D03208, doi:10.1029/2004JD004671, 2005.

Jensen, E. J., Pfister, L., Bui, T. V., Lawson, P., Baker, B., Mo, Q., Baumgardner, D., Weinstock, E. M., Smith, J. B., Moyer, E. J., Hanisco, T. F., Sayres, D. S., Clair, J. M. S., Alexander, M. J., Toon, O. B., and Smith, J. A.: Formation of large $(\simeq 100 \mu \mathrm{m})$ ice crystals near the tropical tropopause, Atmos. Chem. Phys., 8 , 1621-1633, 2008, http://www.atmos-chem-phys.net/8/1621/2008/.

Jensen, E. J., Lawson, P., Baker, B., Pilson, B., Mo, Q., Heymsfield, A., Bansemer, A., Bui, T.-P., McGill, M., Hlavka, D., Heymsfield, G., Platnick, S., Arnold, T., and Tanelli, S.: On the importance of small ice crystals in tropical anvil cirrus, Atmos. Chem. Phys., 9, 5519-5537, 2009,

http://www.atmos-chem-phys.net/9/5519/2009/.

Kärcher, B. and Lohmann, U.: A parameterization of cirrus cloud formation: Homogeneous freezing of supercooled aerosols, J. Geophys. Res., 107, doi:10.1029/2001JD000470, 2002.

Kärcher, B. and Ström, J.: The roles of dynamical variability and aerosols in cirrus cloud formation, Atmos. Chem. Phys., 3, 823838, 2003, http://www.atmos-chem-phys.net/3/823/2003/.

Kay, J. E. and Wood, R.: Timescale analysis of aerosol sensitivity during homogeneous freezing and implications for upper tropospheric water budgets, Geophys. Res. Lett., 35, L10809, doi:10.1029/2007GL032628, 2008.

Koop, T., Luo, B., Tsias, A., and Peter, T.: Water activity as the determinant for homogeneous ice nucleation in aqueous solutions, Nature, 406, 611-614, 2000.

Krämer, M., Schiller, C., Afchine, A., Bauer, R., Gensch, I., Mangold, A., Schlicht, S., Spelten, N., Sitnikov, N., Boormann, S., 
de Reus, M., and Spichtinger, P.: Ice supersaturations and cirrus cloud crystal numbers, Atmos. Chem. Phys., 9, 3505-3522, 2009, http://www.atmos-chem-phys.net/9/3505/2009/.

Lawson, R. P., O'Connor, D., Zmarzly, P., Weaver, K., Baker, B. A., Mo, Q., and Jonsson, H.: The 2D-S (Stereo) probe: Design and preliminary tests of a new airborne, high-speed, high-resolution imaging probe, J. Atmos. Ocean. Tech., 23, 1462-1477, 2006.

Lawson, R. P., Pilson, B., Baker, B. A., Mo, Q., Jensen, E. J., Pfister, L., and Bui, P.: Aircraft measurements of microphysical properties of subvisible cirrus clouds in the tropical tropopause layer, Atmos. Chem. Phys., 8, 1609-1620, 2008, http://www.atmos-chem-phys.net/8/1609/2008/.

Massie, S., Gille, J., Craig, C., Khosravi, R., Barnett, J., and Read, W.: HIRDLS and CALIPSO observations of tropical cirrus, J. Geophys. Res., 1, in press, 2009.

McFarquhar, G. M., Heymsfield, A. J., Spinhirne, J., and Hart, B.: Thin and subvisual tropopause cirrus: Observations and radiative impacts, J. Atmos. Sci., 57, 1841-1853, 2000.

McFarquhar, G. M., Um, J., Freer, M., Baumgardner, D., Kok, G. L., and Mace, G.: The importance of small ice crystals to cirrus properties: Observations from the Tropical Warm Pool International cloud Experiment (TWP-ICE), Geophys. Res. Lett., 57, L13803, doi:10.1029/2007GL029865, 2007.

Möhler, O., Field, P. R., Connolly, P., Benz, S., Saathoff, H., Schnaiter, M., and Wagner, R.: Efficiency of the deposition mode ice nucleation on mineral dust particles, Atmos. Chem. Phys., 6, 3007-3021, 2006, http://www.atmos-chem-phys.net/6/3007/2006/.

Möhler, O., Benz, S., Saathoff, H., Schnaiter, M., Wagner, R., Schneider, J., Walter, S., Ebert, V., and Wagner, S.: The effect of organic coating on the heterogeneous ice nucleation efficiency of mineral dust aerosols, Environ. Res. Lett., 3, 02500, doi:10.1088/1748-9326/3/2/025007, 2008.

Murphy, D. M.: Dehydration in cold clouds is enhanced by a transition from cubic to hexagonal ice, Geophys. Res.Lett., 30, doi:10.1029/2003GL018 566, 2003.

Poole, L. R., Pitts, M. C., and Thomason, L. W.: Comment on "A tropical 'NAT-like' belt observed from space" by H. Chepfer and V. Noel, Geophys. Res. Lett., 36, L20803, doi:10.1029/2009GL038506, 2009.
Reagan, J. A., Wang, X., and Osborn, M. T.: Spaceborne Lidar Calibration From Cirrus and Molecular Backscatter Returns, IEEE Trans. Geosci., 40, 2285-2290, 2002.

Roberts, P. and Hallett, J.: A laboratory study of the ice nucleation properties of some mineral particles, Q. J. Roy. Meteorol. Soc., 94, 25-34, 1968.

Scott, S. G., Bui, T. P., Chan, K. R., and Bowen, S. W.: The meteorological measurement systemon the NASA ER-2 aircraft, J. Atmos. Ocean. Tech., 7, 525-540, 1990.

Selkirk, H. B.: The tropopause cold trap in the Australian monsoon during STEP/AMEX 1987, J. Geophys. Res., 98, 8591-8610, 1993.

Sherwood, S. C., Horinouchi, T., and Zeleznik, H. A.: Convective impact on temperatures observed near the tropical tropopause, J. Atmos. Sci., 60, 1847-1856, 2003.

Spichtinger, P. and Gierens, K.: Modelling of cirrus clouds - Part 1b: Structuring cirrus clouds by dynamics, Atmos. Chem. Phys., 9, 707-719, 2009, http://www.atmos-chem-phys.net/9/707/2009/.

Takahama, S., Pathak, R. K., and Pandis, S. N.: Efflorescence transitions of ammonium sulfate particles coated with secondary organic aerosols, Environmental Science and Technology, 41, 2289-2295, 2007.

Wang, P.-H., Minnis, P., McCormick, M. P., Kent, G. S., and Skeens, K. M.: A 6-year climatology of cloud occurrence frequency from Stratospheric Aerosol and Gas Experiment II observations (1985-1990), J. Geophys. Res., 101, 29407-29429, 1996.

Wise, M. E., Baustian, K. J., and Tolbert, M. A.: Laboratory studies of ice formation pathways from ammonium sulfate particles, Atmos. Chem. Phys., 9, 1639-1646, 2009, http://www.atmos-chem-phys.net/9/1639/2009/.

Yang, Q., Fu, Q., and Hu, Y.: Radiative impacts of clouds in the tropical tropopause layer, J. Geophys. Res., 1, in press, 2009.

Young, S. A. and Vaughan, M. A.: The retrieval of profiles of particulate extinction from Cloud Aerosol Lidar Infrared Pathfinder Satillite Observations (CALIPSO) data: Algorithm description, J. Atmos. Ocean. Tech., 26, 1105-1119, doi:10.1175/2008JTECHA1221.1, 2009. 